\title{
Eating pathology in midlife women: similar or different to younger counterparts?
}

Article

Accepted Version

Jenkins, P. E. and Price, T. (2018) Eating pathology in midlife women: similar or different to younger counterparts? International Journal of Eating Disorders, 51 (1). pp. 3-9. ISSN 0276-3478 doi: https://doi.org/10.1002/eat.22810 Available at https://centaur.reading.ac.uk/76081/

It is advisable to refer to the publisher's version if you intend to cite from the work. See Guidance on citing.

Published version at: http://dx.doi.org/10.1002/eat.22810

To link to this article DOI: http://dx.doi.org/10.1002/eat.22810

Publisher: Wiley

All outputs in CentAUR are protected by Intellectual Property Rights law, including copyright law. Copyright and IPR is retained by the creators or other copyright holders. Terms and conditions for use of this material are defined in the End User Agreement.

\section{www.reading.ac.uk/centaur}

\section{CentAUR}

Central Archive at the University of Reading

Reading's research outputs online 
$1 \quad$ Eating pathology in midlife women: similar or different to younger counterparts?

4 Paul E. Jenkins ${ }^{* 1,2}$

5 Tom Price P $^{1,3}$

6

$7 \quad{ }^{1}$ Cotswold House Eating Disorders Service, Oxford Health NHS Foundation Trust,

8 Oxford, United Kingdom.

92 School of Psychology, University of Birmingham, Birmingham, United Kingdom.

10 3nstitute of Psychiatry, Psychology and Neuroscience, King's College London,

11 United Kingdom.

*Present address: School of Psychology and Clinical Language Sciences, University

14 of Reading, RG6 6AL, UK. E-mail: pej106@gmail.com

16 Word Count (Abstract): 158

17 Word Count (Main Text): 3438 


\section{Abstract}

2 Objective: This study examined potential similarities and differences between

3 women with eating disorders (EDs) in midlife and their younger counterparts.

4 Method: Seven hundred and three women assessed by a specialist eating disorder

5 service were divided into 3 groups based on age $(18-25,25-40$, and $40+)$ and

6 compared on a number of clinical and demographic measures. Distribution of ED

7 diagnoses was also examined between groups.

8 Results: Midlife women were less likely to receive a diagnosis of anorexia nervosa

9 and more likely to receive a diagnosis of binge-eating disorder than their younger counterparts. Duration of illness was longer and age of ED onset later in the midlife

11 group but no differences were seen on measures of global ED pathology,

12 psychosocial impairment, or psychological distress.

13 Discussion: This study adds to the developing literature concerning EDs in midlife 14 women, although further work is needed to support the findings presented here and 15 to examine profiles of males presenting to treatment centres.

17 Keywords: middle-age, midlife, diagnosis, age of onset, anorexia nervosa, bulimia nervosa, binge-eating disorder

\section{Acknowledgements}

21 The authors would like to thank Ceri Morgan for assistance in data collection and 22 analysis. 
2 Incidence of eating disorders (EDs) is commonly associated with younger women,

perhaps due to the relatively early typical age of onset and the gender disparity frequently seen (e.g., Fairburn \& Harrison, 2003). However, studies of women in midlife (a commonly used range is $35-55 y$, although definitions often vary) suggest that around 5\% meet diagnostic criteria for an ED, with greater numbers falling within the spectrum of eating disturbance (Mangweth-Matzek et al., 2014; see also Larrañaga, Docet, \& García-Mayor, 2012; McGuinness \& Taylor, 2016; Marcus et al., 2007; Slof-Op't Landt et al., 2017). Distinct symptoms, such as binge eating and fear of weight gain, have been found to occur in more than $10 \%$ of midlife women (e.g., Fairweather-Schmidt, Lee, \& Wade, 2015; de Freitas et al., 2008; Marcus et al., 2007) and a number of studies suggest that admission rates of midlife women to ED units have increased markedly in recent decades (e.g., Ackard et al., 2013; Cumella \& Kally, 2008).

Given these concerning statistics, alongside findings that older age is associated with poorer outcome (e.g., Ackard et al., 2014; Marcus et al., 2007), it is perhaps surprising that there exists little information on the characteristics of midlife women presenting for outpatient ED treatment. Elran-Barak et al. (2015) looked at individuals seeking treatment at one of four sites in the USA, finding that prevalence of bulimia nervosa $(\mathrm{BN})$ was lower in midlife individuals (age $\geq 40$ years) than a younger sample (18 - 25 years of age), but that binge-eating disorder (BED) and atypical EDs were more common. Prevalence of anorexia nervosa (AN) did not differ between groups. This study provided important information on diagnostic prevalence, but only reported comparisons between younger and older women within diagnostic groups. Therefore, more information is needed concerning whether 
1 midlife women differ from younger groups in degree of ED pathology, for example.

2 Elran-Barak et al. also highlighted the need for more research investigating age of onset and psychological comorbidity, which may have implications for treatment design and provision.

\section{Looking specifically at inpatient admissions, contrasting findings were} presented by Ackard et al. (2013, Study 1 ) who found that midlife patients (40 years or older) were more likely to present with $\mathrm{BN}$ than their younger counterparts (18 39y). The same authors also reported on a sample of 164 women presenting for any level of treatment (Study 2), finding few differences between the two groups in terms of self-esteem, depression, anxiety, and eating pathology. However, Ackard and colleagues did find that age of onset was higher in midlife compared to a younger group (21.4y vs. 17.0y) and that duration of illness was also different (26.5y vs. 8.1y) (see also Forman \& Davis, 2005). It would be expected, though, that duration of illness would typically be longer in midlife samples seeking treatment as, irrespective of age at onset, midlife women have lived longer than their younger counterparts. It seems, then, that data on whether diagnostic prevalence differs between midlife and younger samples is limited, and at times conflicting. Studies on midlife women, generally considered as those aged over 40 years old (Elran-Barak et al., 2015), have tended to focus on more broadly-defined eating pathology (Slevec \& Tiggemann, 2011), with many concerned only with community samples or those presenting for residential treatment. Some data suggest that midlife women report fewer concerns about body shape compared to younger patients but may experience poorer quality of life, and higher levels of psychological distress and interpersonal problems (e.g., Ackard et al., 2014). Other equivocal data concern age of onset, with some studies finding older age of onset (and longer duration of illness) in midlife 
samples. This contrasts with data suggesting that age of onset in some EDs is decreasing (e.g., Favaro et al., 2009) and might suggest that there is a subgroup of older individuals who develop an ED later in life (i.e., late onset; see Gupta, 1990; Bueno et al., 2014). Such 'late onset' EDs have been variously defined as over 40 years old (Kally \& Cumella, 2008) or over 25 years old (Bueno et al., 2014), reflecting the view that age of onset is notoriously "difficult to determine with any precision in most cases" (Arcelus, Mitchell, \& Wales, 2011, p. 729).

Given the small number of studies, it is perhaps unsurprising that some contradictions have arisen. Differences between the studies of Ackard et al. (2013) and Elran-Barak et al. (2015) may have been due to how age groups were split Ackard et al. compared adults over 40 with those under 40 whereas Elran-Barak et al. looked at three groups $(18-25,26-39$, and $40+)$, which may lead to contradictions in interpretation, particularly if those aged $18-25$ present differently to older groups. Furthermore, the upper age was different between the studies and nearly half of those presenting for treatment in the study of Ackard et al. received inpatient treatment, which is unlikely to be representative of many treatment programs in the UK at least (e.g., Robinson, 1993).

The lack of information on midlife women led one group of authors to conclude recently that "our understanding of the needs of [middle-aged] women seeking treatment is in its nascence" (Ackard et al., 2013, p. 177). The current study aims to look in detail at individuals in midlife who attend for specialist treatment of an ED. It will present data on the distribution of different ED diagnoses and will compare midlife women with younger women on a number of clinical and demographic measures. Given conflicting methods in existing empirical work, the study will compare three age groups (i.e., $18-25,25-40,40+$ ), using 40 years of 
1 age as a common definition of midlife (e.g., Elran-Barak et al., 2015; Kally \&

2 Cumella, 2008). The method of dividing the sample into three separate groups was chosen in order to include the full age spectrum, whilst being able to look at differences between clearly-defined age groups that have been previously studied (cf., Elran-Barak et al., 2015). We were also interested in whether age differences existed between those who did and did not attend their initial assessment as this has important implications for accessing treatment. Given limited findings to-date, we hypothesised that BED would be more common in the midlife group. In line with others (Mangweth-Matzek et al., 2014) our clinical experience suggests that midlife women present with similar levels of symptoms and impairment to younger samples, and were interested to see whether this was substantiated in a large, treatmentseeking sample.

Methods

\section{Participants}

Participants were referred to an outpatient eating disorders service based in the UK.

This service offers specialist, evidence-based treatment to adults with an ED, including guided self-help, cognitive behaviour therapy, and interpersonal psychotherapy. Some individuals referred to the service will subsequently be referred for more intensive treatment (e.g., inpatient care). Between April 2014 and April 2017, 896 outpatient referrals were received, the majority of which came from primary care $(n=641 ; 74.8 \%)$. In line with the study's primary aims, for remaining analyses only those who attended for assessment were included. Men $(n=47$;

$6.3 \%$ ) were also excluded due to relatively small numbers. Participants were subsequently stratified by age into 3 groups: 18 to 25 years $(54.3 \%$; $n=382), 25$ to 
140 years $(28.4 \%, n=200)$ and 40 years and above $(17.2 \%, n=121)$. The study was approved by the local NHS Quality and Audit Team.

\section{$4 \quad$ Procedures}

5 Individuals met with a qualified clinician (e.g., nurse specialist, psychologist,

6 psychiatrist) who established diagnosis following a semi-structured interview

7 according to criteria for feeding and eating disorders (DSM-5; APA, 2013). Twenty-

8 nine of those who attended assessment (4.1\%) did not meet criteria for an ED.

9 Additional information collected included age and self-reported age at onset of ED

10 (although the procedure for identifying the latter was not standardised); duration of

11 illness was calculated as the difference. Of 611 individuals who provided this information, 317 (51.9\%) reported having received previous treatment. Weight and height were measured with calibrated scales, used to calculate body mass index $\left(\mathrm{BMI} ; \mathrm{kg} / \mathrm{m}^{2}\right)$. In advance of this appointment, each individual was sent a self-report questionnaire pack which they were invited to complete although not all individuals did so.

The Eating Disorder Examination - Questionnaire (EDE-Q; Fairburn \& Beglin, 1994) is a 36-item measure assessing behavioural and cognitive symptoms of eating pathology experienced in the last 28 days. The EDE-Q produces a number of behavioural indices (e.g., objective binge eating, self-induced vomiting) as well as four subscales (Restraint, Eating Concern, Shape Concern, Weight Concern). Subscales are rated on a six-point Likert scale, with higher scores indicative of greater symptomatology. A Global score can be calculated from the cognitive items, which provides a general index of ED pathology. Due to strong correlation $(r=0.88)$ between the Shape Concern and Weight Concern subscales, a combined 
1 'Weight/Shape Concern' subscale was derived from the mean of all 12 items (e.g.,

2 see Berg, Peterson, Frazier, \& Crow, 2012). Cronbach's $\alpha$ in the current sample were as follows: Restraint, 0.82; Eating Concern, 0.77; and Weight/Shape Concern, 0.92 .

The Clinical Impairment Assessment questionnaire (CIA; Bohn \& Fairburn, 2008) assesses severity of psychosocial impairment attributable to ED symptoms experienced over the last 28 days. The measure has shown good psychometric properties in comparable samples (Jenkins, 2013), and the 16 items are rated on a 0-3 scale, with higher scores indicating greater levels of impairment. A cut-off of 16 has been suggested to predict ED case status (Bohn et al., 2008). Cronbach's $\alpha$ was 0.92 .

The Clinical Outcomes in Routine Evaluation-Outcome Measure (CORE-OM; Barkham et al., 2001) is a 34-item scale, which provides a measure of general psychological distress experienced over the previous 7 days. Items are scored from 0 to 4 and provide a total score, calculated as the mean of all items multiplied by 10 (see Connell et al., 2007). A cut-off of 10 is recommended to indicate clinical significance and its utility in the study of individuals with EDs has been established (Jenkins \& Turner, 2014). Cronbach's a was 0.95.

\section{Statistical Analyses}

$\mathrm{X}^{2}$ tests were used to examine differences among groups on categorical variables (e.g., diagnoses, assessment attendance) and continuous data (e.g., age of onset, EDE-Q scores) were analysed with Kruskal-Wallis or Mann-Whitney procedures due to non-normal distribution of data. Significant differences were explored using post 
1 hoc Mann-Whitney $U$ tests. Significance level was set at $p<.05$ and all tests were conducted using SPSS Version 22.

\section{Results}

\section{$5 \quad$ Attendance at First Assessment}

$6 \quad$ There were no significant differences between those who attended their initial

7 assessment $(n=750)$ and those who did not $(n=146)$ in terms of age (mean (SD) $=$ 28.2y (11.1y) vs. 28.6y (11.5y), $U=52540.500, z=-.774, p=.439)$ or gender (93.7\% female vs. $89.7 \%$ female, $\left.X^{2}(1)=3.047, p=.081\right)$.

\section{Diagnostic Differences}

As summarised in Table 1, those aged $18-25$ were more likely to be diagnosed with AN than other groups $\left(X^{2}(1)=8.92, p=.003\right)$. Those aged $25-40$ were equally likely as other groups to be diagnosed with $\mathrm{AN}\left(\mathrm{X}^{2}(1)=0.24, \mathrm{p}=.63\right)$, and midlife women were less likely to receive an AN diagnosis $\left(X^{2}(1)=11.28, p=.001\right)$. There were no group differences regarding proportions of $B N\left(x^{2}(2)=1.284, p=\right.$ groups $\left(x^{2}(1)=13.67, p=<.001\right)$. Those aged $25-40$ were equally likely to be diagnosed with BED $\left(X^{2}(1)=0.02, p=.90\right)$ as other age groups. Midlife women $.48)$. 


\section{Previous Treatment}

2 Results found no differences between age groups regarding receipt of previous

3 treatment $\left(x^{2}(2)=1.69, p=.431\right)$; see Table 2 .

$5 \quad$ Markers of Disordered Eating

6 As shown in Table 2, BMI differed across groups $(\mathrm{H}(2)=17.48, p<.001)$, with post

7 hoc analyses finding that the youngest group (18 - 25y) was lower than both other

8 groups, which were statistically equivalent. Duration of illness differed across groups

$9 \quad(H(2)=207.76, p<.001)$, with post hoc analyses finding that all groups differed from

10 each other. Scores on the Global scale of the EDE-Q were equivalent $(H(2)=3.89$, $p=0.14)$. Weight and Shape Concerns differed across groups $(H(2)=7.68, p=$ 0.021 ), and Mann-Whitney tests found that the youngest group (18 - 25y) had lower scores than the other two groups, which were statistically equivalent.

INSERT TABLE 2

\section{Psychological Distress and Psychosocial Impairment}

Scores on the CORE-OM $(H(2)=3.20, p=0.202)$ and $\mathrm{CIA}(\mathrm{H}(2)=2.47, p=0.292)$

were equivalent across groups. Degree of distress and impairment was high within the sample, with 498 of 559 (89.1\%) individuals scoring above 10 on the CORE-OM, and 501 of $560(89.5 \%)$ scoring above 16 on the CIA.

\section{Age of Onset}

Age of onset was different across groups $(H(2)=10.32, p=.006)$, with the youngest group (18 - 25y) reporting a younger age of onset than the other two groups, which 
1 were statistically equivalent. Of 307 individuals for whom data were available, only 2

$2(0.7 \%)$ were documented as having an ED onset over 40 years of age and $20(6.5 \%)$ over the age of 25. Statistical comparisons between groups were therefore not performed. However, for those with an onset over 25 , seven $(35.0 \%)$ had AN, four $(20.0 \%) B N$, and the remainder 'other EDs' $(n=9 ; 45.0 \%)$. There were no individuals with BED with a reported onset after 25 years of age.

\section{Discussion}

The current study aimed to describe the characteristics of women in midlife who present for treatment of EDs. Overall, slightly fewer than $20 \%$ of individuals assessed for treatment were aged over 40 and, of these, just over one-third presented with atypical or 'other' eating disorders.

Comparison with existing studies suggests that the proportion of atypical EDs is similar, at around 30 - 40\% (see Ackard et al., 2013; Elran-Barak et al., 2015), but proportions of other diagnoses were more variable. For example, similar numbers of BN were observed between the current study (20.7\%) and that of Ackard et al. (2013) (16.7\%), with slightly higher rates (29.9\%) reported by Elran-Barak et al. (2015). Regarding BED, the results presented here concur with those of Elran-Barak et al. in suggesting that women in midlife are more likely to be diagnosed with BED than younger individuals. Findings regarding AN are more equivocal, partly confounded by the fact that many studies have included inpatient samples, which are likely to report a higher proportion of individuals with AN (e.g., Cumella \& Kally, 2008). However, the finding reported here that women in midlife are less likely to be diagnosed with AN has been reported previously (Ackard et al., 2014; cf. ElranBarak et al., 2015). 
Looking at ED symptoms, results suggest that midlife women present perhaps as more similar than they are different compared to younger groups (see also Perez, Hernandez, Clarke, \& Joiner, 2007). Although levels of ED pathology, as measured by the Global scale of the EDE-Q, were similar, the youngest group (18-25y) reported lower weight and shape concerns than the older groups, which were equivalent, a finding similar to that of Tiggemann and Stevens (1999) in a sample of 180 women aged between $18-60$. Similar patterns were also evident in BMI and age of onset. The finding that duration of illness is longer (e.g., Cumella \& Kally, 2008; Forman \& Davis, 2005) was supported, suggesting that women in midlife presenting for treatment have lived with the illness for longer than their younger counterparts, which might negatively affect treatment outcome (e.g., Reas, Williamson, Martin, \& Zucker, 2000). Although this should not be taken as evidence that older women cannot benefit from treatment, it does suggest that greater efforts should be made to intervene with disordered eating at earlier stages of the illness. The finding of a longer duration of illness, however, is confounded by obvious age differences between groups. Indeed, mean duration of illness (27.4y) of the oldest group exceeded the upper age limit for the youngest group.

Many of these findings, however, should be seen in the context of the distribution of ED diagnoses. For example, it is likely that differences in BMI, for example, were strongly related to the higher prevalence of $\mathrm{AN}$ in the younger sample and BED in the older samples. However, as BMI increases with age (Deurenberg, Weststrate, \& Seidell, 1991), this conclusion cannot be confirmed in the current study. Interestingly, the current study showed that all age groups were equivalent on measures of psychological distress and impairment (cf. Ackard et al., 2014), and 
1 scores for the midlife group were in line with other studies of ED samples (e.g.,

2 Jenkins, 2013; Jenkins \& Turner, 2014), again suggestive of similarity. Investigating age of onset within EDs was a secondary aim of the study, although this is difficult to determine accurately (Arcelus et al., 2011) and the procedure was not standardised in the current study. Given these caveats, relatively small numbers of 'late onset' cases were seen, with smaller proportions than previous work (e.g., Bueno et al., 2014; Kimura et al., 2007). Of particular note, there were no cases of 'late onset' BED in this large sample, although this has been documented (e.g., Beck, Casper, \& Andersen, 1996) and more work is required in this area given what little is known (Bueno et al., 2014). In addition to possibly being related to diagnostic distribution within the different age groups, findings may also reflect different referral, identification, and assessment practices across time periods. Thus, the possibility that cohort effects influenced findings represents a limitation of and impairment across the age range.

The current study adds to the literature in a number of ways. Firstly, it presents information from a large sample of women regarding prevalence of ED diagnoses and symptoms, showing similar figures to existing work (e.g., Ackard et al., 2014). However, it also goes beyond this by including a large sample of women presenting for outpatient treatment and looking at both diagnostic breakdown (e.g., Elran-Barak et al., 2015) and wider symptoms. The study presents data on three distinct age groups, perhaps revealing interesting similarities amongst those aged over 25. Finally, it reviewed age of onset, although found few individuals reporting illness onset beyond 25 years of age, which warrants further research. Some shortcomings and limitations should be noted. As men were omitted from this study, 
1 this perhaps lends support to the idea that "men aged midlife and beyond might be

2 the most stigmatized group to suffer from an eating disorder" (Reas \& Stedal, 2015,

p. 254). The study was limited by use of retrospective review of routinely-referred patients within an outpatient setting in the UK, particularly as results may differ across settings (e.g., inpatients, or primary care). As sociocultural factors have been associated with presentation of different EDs (e.g., Hoek et al., 1995), further studies might seek to replicate the findings reported here. In addition, a large proportion of individuals indicated that they had previously received treatment for an ED, although this proportion is similar to other tertiary centres in the UK (e.g., Treasure, Schmidt, Troop, Tiller, Todd, \& Turnbull, 1996) and clinics in the US (e.g., Crow, Mussell, Peterson, Knopke, \& Mitchell, 1999). Differences with previous work might reflect this methodological aspect but could also be related to the diagnostic criteria used (i.e., DSM-IV vs. DSM-5).

Results of the study argue for continued attention to reducing barriers to accessing treatment and identifying cases as early as possible (e.g., Reas et al., 2000). A recent study highlighted the importance of adequate healthcare provision with regards to women in midlife (Micali et al., 2017), and thus the present findings serve as a continued reminder that EDs occur across the age range. Further studies might look at whether EDs in older individuals are being correctly identified, and whether current psychological therapies are sufficiently personalised to address the needs of all those presenting for ED treatment. Given the similarities across groups noted here, it likely that many core strategies will remain relevant and effective for women in midlife, but age-related differences may warrant consideration.

In summary, this study suggests that midlife women are more similar than different to their younger counterparts, although older women appear more likely to 
1 present with BED. Degree of global eating pathology, ED-related psychosocial

2 impairment, and psychological distress remained similar across the age range.

3 Further work in this area is needed, particularly concerning age of onset and 4 inclusion of male samples. 
American Psychiatric Association. (2013). Diagnostic and statistical manual of mental disorders (5th ed.). Washington, DC.

Ackard, D. M., Richter, S., Frisch, M. J., Mangham, D., \& Cronemeyer, C. L. (2013). Eating disorder treatment among women forty and older: Increases in prevalence over time and comparisons to young adult patients. Journal of Psychosomatic Research, 74(2), 175-178. DOI:

10.1016/j.jpsychores.2012.10.014.

Ackard, D. M., Richter, S., Egan, A., \& Cronemeyer, C. (2014). Poor outcome and death among youth, young adults, and midlife adults with eating disorders: an investigation of risk factors by age at assessment. International Journal of Eating Disorders, 47(7), 825-835. DOI: 10.1002/eat.22346.

Arcelus, J., Mitchell, A. J., Wales, J., \& Nielsen, S. (2011). Mortality rates in patients with anorexia nervosa and other eating disorders: A meta-analysis of 36 studies. Archives of General Psychiatry, 68(7), 724-731. DOI: 0.1001/archgenpsychiatry.2011.74.

Barkham, M., Margison, F., Leach, C., Lucock, M., Mellor-Clark, J., Evans, C., . . . McGrath, G. (2001). Service profiling and outcomes benchmarking using the CORE-OM: toward practice-based evidence in the psychological therapies. Journal of Consulting and Clinical Psychology, 69(2), 184-196.

Beck, D., Casper, R., \& Andersen, A. (1996). Truly late onset of eating disorders: a study of 11 cases averaging 60 years of age at presentation. International Journal of Eating Disorders, 20(4), 389-395. 
1 Berg, K. C., Peterson, C. B., Frazier, P., \& Crow, S. J. (2012). Psychometric evaluation of the Eating Disorder Examination and Eating Disorder Examination-Questionnaire: a systematic review of the literature. International Journal of Eating Disorders, 45(3), 428-438. DOI: 10.1002/eat.20931.

Bohn, K., \& Fairburn, C.G. (2008). The clinical impairment assessment questionnaire (CIA 3.0). In: Fairburn, C.G. (Ed.), Cognitive Behaviour Therapy and Eating Disorders. Guilford Press, New York, 315-317.

Bohn, K., Doll, H. A., Cooper, Z., O'Connor, M., Palmer, R. L., \& Fairburn, C. G. (2008). The measurement of impairment due to eating disorder psychopathology. Behaviour Research and Therapy, 46(10), 1105-1110. DOI: 10.1016/j.brat.2008.06.012.

Bueno, B., Krug, I., Bulik, C. M., Jiménez-Murcia, S., Granero, R., Thornton, L., . . Fernández-Aranda, F. (2014). Late onset eating disorders in Spain: Clinical characteristics and therapeutic implications. Journal of Clinical Psychology, 7O(1), 1-17. DOI: 10.1002/jclp.22006.

Connell, J., Barkham, M., Stiles, W. B., Twigg, E., Singleton, N., Evans, O., Miles, J. N. V. (2007). Distribution of CORE-OM scores in a general population, clinical cut-off points and comparison with the CIS-R. British Journal of Psychiatry, 190(1), 69-74. DOI: 10.1192/bjp.bp.105.017657.

Crow, S., Mussell, M. P., Peterson, C., Knopke, A., \& Mitchell, J. (1999). Prior treatment received by patients with bulimia nervosa. International Journal of 
Eating Disorders, 25, 39-44. DOI: 10.1002/(SICI)1098-

108X(199901)25:1<39::AID-EAT5>3.0.CO;2-W

Cumella, E. J., \& Kally, Z. (2008). Profile of 50 women with midlife-onset eating disorders. Eating Disorders, 16(3), 193-203. DOI: $10.1080 / 10640260802016670$

de Freitas, S. R., Appolinario, J. C., Souza A. d. M., \& Sichieri, R. (2008). Prevalence of binge eating and associated factors in a Brazilian probability sample of midlife women. International Journal of Eating Disorders, 41(5), 471-478. DOI: 10.1002/eat.20530.

Deurenberg, P., Weststrate, J. A., \& Seidell, J. C. (1991). Body mass index as a measure of body fatness: age- and sex-specific prediction formulas. British Journal of Nutrition, 65(2), $105-114$.

Elran-Barak, R., Fitzsimmons-Craft, E. E., Banyamini, Y., Crow, S. J., Peterson, C. B., Hill, L. J., Crosby, R. D., Mitchell, J. E., \& Le Grange, D. (2015). Anorexia nervosa, bulimia nervosa, and binge eating disorder in midlife and beyond. The Journal of Nervous and Mental Disease, 203(8), 1-8. DOI: 10.1097/NMD.0000000000000333.

Fairburn, C.G., \& Beglin, S.J. (1994). Assessment of eating disorders: interview or self-report questionnaire? International Journal of Eating Disorders, 16(4), 363-370.

Fairburn, C. G., \& Harrison, P. J. (2003). Eating disorders. The Lancet, 361(9355), 407-416. DOI: 10.1016/s0140-6736(03)12378-1. 
1 Favaro, A., Caregaro, L., Tenconi, E., Bosello, R., \& Santonastaso, P. (2009). Time trends in age at onset of anorexia nervosa and bulimia nervosa. Journal of Clinical Psychiatry, 70(12), 1715-21. DOI: 10.4088/JCP.09m05176blu.

Fairweather-Schmidt, A. K., Lee, C., \& Wade, T. D. (2015). A longitudinal study of midage women with indicators of disordered eating. Developmental Psychology, 51(5), 722-729. DOI: 10.1037/dev0000011.

Forman, M. E., \& Davis, W. N. (2005) Characteristics of Middle-Aged Women in Inpatient Treatment for Eating Disorders. Eating Disorders, 13(3), 231-243, DOI: $10.1080 / 10640260590932841$.

Gupta, M. A. (1990). Fear of aging: a precipitating factor in late onset anorexia nervosa. International Journal of Eating Disorders, 9(2), 221-224. DOI: 10.1002/1098-108X(199003)9:2<221::AID-EAT2260090213>3.0.CO;2-K.

Hoek, H. W., Bartelds, A. I. M., Bosveld, J. J. F., van der Graaf, Y., Limpens, V. E. L., Maiwald, M., \& Spaaij, C. J. K. (1995). Impact of urbanization on detection rates of eating disorders. The American Journal of Psychiatry, 152(9), 12721278.

Jenkins, P. E. (2013). Psychometric validation of the Clinical Impairment Assessment in a UK eating disorder service. Eating Behaviours, 14(2), 241243. DOI: 10.1016/j.eatbeh.2012.12.001.

Jenkins, P. E., \& Turner, H. M. (2014). An investigation into the psychometric properties of the CORE-OM in patients with eating disorders. Counselling and Psychotherapy Research, 14(2), 102-110. DOI: 10.1080/14733145.2013.782057. 
1 Kally, Z., \& Cumella, E. J. (2008). 100 midlife women with eating disorders: A phenomenological analysis of etiology. The Journal of General Psychology, 135(4), 359-377.DOI: 10.3200/GENP.135.4.359-378.

Kimura, H., Tonoike, T., Muroya, T., Yoshida, K., Ozaki, N. (2007). Age of onset has limited association with body mass index at time of presentation for anorexia nervosa: Comparison of peak-onset and late-onset anorexia nervosa groups. Psychiatry and Clinical Neuroscience, 61(6), 646-50.

Larrañaga, A., Docet, M. F., \& García-Mayor, R. V. (2012). High prevalence of eating disorders not otherwise specified in north western Spain: populationbased study. Social Psychiatry and Psychiatric Epidemiology, 47(10), 166973. DOI: $10.1007 / \mathrm{s} 00127-012-0473-1$.

McGuinness, S., \& Taylor, J. E. (2016). Understanding body image dissatisfaction and disordered eating in midlife adults. New Zealand Journal of Psychology, 45(1), 4-12.

Mangweth-Matzek, B., Hoek, H. W., Rupp, C. I., Lackner-Seifert, K., Frey, N., Whitworth, A. B., Pope, H. G., Jr., \& Kinzl J. (2014). Prevalence of eating disorders in middle-aged women. International Journal of Eating Disorders, 47(3), 320-324. DOI: 10.1002/eat.22232.

Marcus, M. D., Bromberger, J. T., Wei, H.-L., Brown, C., \& Kravitz, H. M. (2007). Prevalence and selected correlates of eating disorder symptoms among a multiethnic community sample of midlife women. Annals of Behavioral Medicine, 33(3), 269-277. 
Micali, N., Martini, M. G., Thomas, J. J., Eddy, K. T., Kothari, R., Russell, E., . . Treasure, J. (2017). Lifetime and 12-month prevalence of eating disorders amongst women in mid-life: a population-based study of diagnoses and risk factors. BMC Medicine, 15, 12. DOI: 10.1186/s12916-016-0766-4

Perez, M., Hernandez, A., Clarke, A., \& Joiner, T. E., Jr. (2007). Analysis of bulimic symptomatology across age and geographic locations. Eating Behaviors, 8(1), 136-142.

Reas, D. L., \& Stedal, K. (2015). Eating disorders in men aged midlife and beyond. Maturitas, 81(2), 248-255. DOI: 0.1016/j.maturitas.2015.03.004.

Reas, D. L., Williamson, D. A., Martin, C. K., \& Zucker, N. L. (2000). Duration of illness predicts outcome for bulimia nervosa: a long-term follow-up study. International Journal of Eating Disorders, 27, 428-434. DOI: 10.1002/(SICI)1098-108X(200005)27:4<428::AID-EAT7>3.0.CO;2-Y.

Robinson, P. (1993). Treatment for eating disorders in the United Kingdom: Part I. A survey of specialist services. Eating Disorders Review, 1(1), 4-9. DOI: 10.1002/erv.2400010103.

Slevec, J., \& Tiggemann, M. (2011). Media Exposure, Body Dissatisfaction, and Disordered Eating in Middle-aged Women: A Test of the Sociocultural Model of Disordered Eating. Psychology of Women Quarterly 35(4) 617-627. DOI: $10.1177 / 0361684311420249$.

Slof-Op't Landt, M. C. T., van Furth, E. F., van Beijsterveldt, C. E. M., Bartels, M., Willemsen, G., de Geus, E. J., Ligthart, L., \& Boomsma, D. I. (2017). Prevalence of dieting and fear of weight gain across ages: a community 

sample from adolescents to the elderly. International Journal of Public Health. DOI: $10.1007 / \mathrm{s} 00038-017-0948-7$.

3 Tiggemann, M., \& Stevens, C. (1999). Weight concern across the life-span: Relationship to self-esteem and feminist identity. International Journal of Eating Disorders, 26(1), 103 - 106.

6 Treasure, J., Schmidt, U., Troop, N., Tiller, J., Todd, G., \& Turnbull, S. (1996). Sequential treatment for bulimia nervosa incorporating a self-care manual. British Journal of Psychiatry, 168, 94-98. DOI: 10.1192/bjp.168.1.94 
1 Table 1. Distribution of diagnoses across age groups

\begin{tabular}{llllll}
\hline \multicolumn{5}{c}{} & \multicolumn{5}{c}{ Age Group } & \multicolumn{2}{c}{ Total Sample } \\
\cline { 2 - 4 } Diagnoses, $\mathrm{n}$ & $(\mathrm{n}=382)$ & $(\mathrm{n}=200)$ & $(\mathrm{n}=121)$ & $(\mathrm{n}=703)$ & $\mathrm{X}^{2}$ \\
\hline AN & $162(42.4 \%)$ & $72(36.0 \%)$ & $29(24.0 \%)$ & $263(37.6 \%)$ & $13.584^{* *}$ \\
BN & $88(23.0 \%)$ & $52(26.0 \%)$ & $25(20.7 \%)$ & $165(23.5 \%)$ & 1.284 \\
BED & $8(2.1 \%)$ & $10(5.0 \%)$ & $16(13.2 \%)$ & $34(4.8 \%)$ & $24.744^{* *}$ \\
Other & $111(29.1 \%)$ & $59(29.5 \%)$ & $42(34.7 \%)$ & $212(30.2 \%)$ & 1.451 \\
No ED & $13(3.4 \%)$ & $7(3.5 \%)$ & $9(7.4 \%)$ & $29(4.1 \%)$ & 4.059
\end{tabular}

2 Note: ${ }^{* *} \mathrm{p}<.01 ; \mathrm{AN}=$ anorexia nervosa; $\mathrm{BN}=$ bulimia nervosa; $\mathrm{BED}=$ binge-eating 3 disorder 
1 Table 2. Demographic and clinical characteristics of women with EDs

\begin{tabular}{|c|c|c|c|c|c|c|}
\hline \multirow[b]{2}{*}{$\begin{array}{l}\text { Demographics, } \\
\text { mean (SD) }\end{array}$} & \multicolumn{3}{|c|}{ Age Group } & \multirow[b]{2}{*}{$\begin{array}{l}\text { Total } \\
\text { Sample }\end{array}$} & \multicolumn{2}{|c|}{ Kruskal-Wallis } \\
\hline & $\begin{array}{l}18-25 y \\
(n=382)^{a}\end{array}$ & $\begin{array}{l}25-40 y \\
(n=200)^{b}\end{array}$ & $\begin{array}{l}40+ \\
(n=121)^{c}\end{array}$ & & $\overline{x^{2}}$ & $\begin{array}{l}\text { Mann- } \\
\text { Whitney }\end{array}$ \\
\hline BMI & $\begin{array}{l}19.16 \\
(4.11)\end{array}$ & $\begin{array}{l}21.30 \\
(6.38)\end{array}$ & $\begin{array}{l}24.13 \\
(10.69)\end{array}$ & $\begin{array}{l}20.59 \\
(6.56)\end{array}$ & $17.476^{* *}$ & $\begin{array}{l}\mathrm{a}<\mathrm{b}, \mathrm{a}< \\
\mathrm{c}, \mathrm{b}=\mathrm{c}\end{array}$ \\
\hline Age of onset & $\begin{array}{l}16.05 \\
(2.91)\end{array}$ & $\begin{array}{l}18.11 \\
(5.70)\end{array}$ & $\begin{array}{l}20.16 \\
(10.09)\end{array}$ & $\begin{array}{l}17.15 \\
(5.35)\end{array}$ & $10.315^{\star *}$ & $\begin{array}{l}a<b, a< \\
c, b=c\end{array}$ \\
\hline DOI & $\begin{array}{l}4.31 \\
(3.27)\end{array}$ & $\begin{array}{l}12.97 \\
(6.82)\end{array}$ & $\begin{array}{l}27.36 \\
(11.16)\end{array}$ & $\begin{array}{l}9.63 \\
(9.65)\end{array}$ & $207.756^{\star *}$ & $a<b<c$ \\
\hline EDE-Q Global & $\begin{array}{l}3.90 \\
(1.40)\end{array}$ & $\begin{array}{l}4.15 \\
(1.26)\end{array}$ & $\begin{array}{l}4.15 \\
(1.31)\end{array}$ & $\begin{array}{l}4.01 \\
(1.35)\end{array}$ & 3.822 & ns \\
\hline WSC & $\begin{array}{l}4.29 \\
(1.51)\end{array}$ & $\begin{array}{l}4.59 \\
(1.37)\end{array}$ & $\begin{array}{l}4.62 \\
(1.40)\end{array}$ & $\begin{array}{l}4.42 \\
(1.46)\end{array}$ & $7.483^{*}$ & $\begin{array}{l}\mathrm{a}<\mathrm{b}, \mathrm{a}< \\
\mathrm{c}, \mathrm{b}=\mathrm{c}\end{array}$ \\
\hline CIA & $\begin{array}{l}31.40 \\
(11.77)\end{array}$ & $\begin{array}{l}32.52 \\
(10.39)\end{array}$ & $\begin{array}{l}33.87 \\
(10.40)\end{array}$ & $\begin{array}{l}32.11 \\
(11.20)\end{array}$ & 2.431 & $n s$ \\
\hline CORE-OM & $\begin{array}{l}18.73 \\
(7.28)\end{array}$ & $\begin{array}{l}19.54 \\
(7.14)\end{array}$ & $\begin{array}{l}20.31 \\
(8.09)\end{array}$ & $\begin{array}{l}19.21 \\
(7.39)\end{array}$ & 3.253 & ns \\
\hline $\begin{array}{l}\text { Previous } \\
\text { treatment, } n\end{array}$ & $\begin{array}{l}178 \\
(51.9 \%)\end{array}$ & $\begin{array}{l}82 \\
(48.8 \%)\end{array}$ & $\begin{array}{l}57 \\
(57.0 \%)\end{array}$ & $\begin{array}{l}317 \\
(51.9 \%)\end{array}$ & 1.685 & - \\
\hline
\end{tabular}

2 Note: Numbers differ across groups as not all individuals completed all measures

$3{ }^{\star} \mathrm{p}<.05,{ }^{*} \mathrm{p}<.01 ; \mathrm{BMI}=$ body mass index; $\mathrm{DOI}=$ duration of illness; $\mathrm{EDE}-\mathrm{Q}=$

4 Eating Disorder Examination - Questionnaire; WSC = Weight and Shape Concern; 
$1 \mathrm{CIA}=$ Clinical Impairment Assessment questionnaire; $\mathrm{CORE}-\mathrm{OM}=$ Clinical 2 Outcomes in Routine Evaluation-Outcome Measure 